\title{
A New Third-Order Derivative Free method for Solving Nonlinear Equations
}

\author{
J. P. Jaiswal \\ Department of Mathematics, Maulana Azad National Institute of Technology, Bhopal-462051, M. P. India \\ ${ }^{*}$ Corresponding Author: asstprofjpmanit@gmail.com
}

Copyright (C2013 Horizon Research Publishing All rights reserved.

\begin{abstract}
In the present paper, by approximating the derivatives in the Newton-Steffensen third-order method by central difference quotient, we obtain a new modification of this method free from derivatives. We prove that the method obtained preserves their order of convergence, without calculating any derivative. Finally, numerical tests confirm that our method give the better performance as compare to the other well known derivative free Steffensen type methods.
\end{abstract}

Keywords Nonlinear Equations, Order of Convergence, Simple Root, Central Difference, Derivative Free Method

Mathematics Subject Classification (2000). 65H05, 65H10, 41A25

\section{Introduction}

A large number of papers have been written about iterative methods for the solution of the nonlinear equations. In this paper, we consider the problem of finding a simple root $x^{*}$ of a function $f: D \subseteq \Re \longrightarrow \Re$, i.e. $f\left(x^{*}\right)=0$ and $f^{\prime}\left(x^{*}\right) \neq 0$. The famous Newton's method for finding $x^{*}$ uses the iterative method

$$
x_{n+1}=x_{n}-\frac{f\left(x_{n}\right)}{f^{\prime}\left(x_{n}\right)},
$$

starting from some initial value $x_{0}$. The Newton's method is an important and basic method which converges quadratically in some neighborhood of simple root $x^{*}$. However, when the first order derivative of the function $f(x)$ is unavailable or is expensive to compute, the Newtons method is still restricted in practical applications. In order to avoid computing the first order derivative, Steffensen in [1] proposed the following derivative-free method. It is well known that the forward-difference approximation for $f^{\prime}(x)$ at $x$ is

$$
f^{\prime}(x) \approx \frac{f(x+h)-f(x)}{h} .
$$

If the derivative $f^{\prime}\left(x_{n}\right)$ is replaced by the forward-difference approximation with $h=f^{\prime}\left(x_{n}\right)$ i.e.

$$
f^{\prime}\left(x_{n}\right) \approx \frac{f\left(x_{n}+f\left(x_{n}\right)\right)-f(x)}{f\left(x_{n}\right)},
$$

the Newton's method becomes

$$
x_{n+1}=x_{n}-\frac{f\left(x_{n}\right)^{2}}{f\left(x_{n}+f\left(x_{n}\right)\right)-f\left(x_{n}\right)},
$$

which is the famous Steffensen's method [1]. The Steffensen's method is based on forward-difference approximation to derivative. This method is a tough competitor of Newton's method. Both the methods are quadratic convergence, both require two functions evaluation per iteration but Steffensen's method is derivative free. The idea of removing derivatives from the iteration process is very significant. Recently, many high order derivative-free methods are built according to the Steffensen's method, see [[2], [3], [4], [5], [6], [7], [8], [9]] and the references therein. 
Jain [7] presented the third-order method (Jain Method):

$$
\begin{aligned}
y_{n} & =x_{n}-\frac{f\left(x_{n}\right)^{2}}{f\left(x_{n}+f\left(x_{n}\right)\right)-f\left(x_{n}\right)}, \\
x_{n+1} & =x_{n}-\frac{f\left(x_{n}\right)^{3}}{\left\{f\left(x_{n}+f\left(x_{n}\right)\right)-f\left(x_{n}\right)\right\}\left\{f\left(x_{n}\right)-f\left(y_{n}\right)\right\}} .
\end{aligned}
$$

Dehghan et al. [8] proposed two third-order Steffensen type method (Dehghan Method I):

$$
\begin{aligned}
y_{n} & =x_{n}-\frac{2 f\left(x_{n}\right)^{2}}{f\left(x_{n}+f\left(x_{n}\right)\right)-f\left(x_{n}-f\left(x_{n}\right)\right)}, \\
x_{n+1} & =x_{n}-\frac{2 f\left(x_{n}\right)\left\{f\left(x_{n}\right)+f\left(y_{n}\right)\right\}}{f\left(x_{n}+f\left(x_{n}\right)\right)-f\left(x_{n}-f\left(x_{n}\right)\right)} .
\end{aligned}
$$

and (Dehghan Method II)

$$
\begin{aligned}
y_{n} & =x_{n}+\frac{2 f\left(x_{n}\right)^{2}}{f\left(x_{n}+f\left(x_{n}\right)\right)-f\left(x_{n}-f\left(x_{n}\right)\right)}, \\
x_{n+1} & =x_{n}-\frac{2 f\left(x_{n}\right)\left\{f\left(y_{n}\right)-f\left(x_{n}\right)\right\}}{f\left(x_{n}+f\left(x_{n}\right)\right)-f\left(x_{n}-f\left(x_{n}\right)\right)} .
\end{aligned}
$$

Again Dehghan et al. [9] introduced a new third-order Steffensen type method (Dehghan Method III):

$$
\begin{aligned}
y_{n} & =x_{n}+\frac{2 f\left(x_{n}\right)^{2}}{f\left(x_{n}+f\left(x_{n}\right)\right)-f\left(x_{n}-f\left(x_{n}\right)\right)}, \\
x_{n+1} & =x_{n}-\frac{2 f\left(x_{n}\right)}{f\left(y_{n}\right) f(u)+f\left(x_{n}\right) f(v)},
\end{aligned}
$$

where $f(u)=f\left(x_{n}+f\left(x_{n}\right)\right)-f\left(x_{n}-f\left(x_{n}\right)\right)$ and $f(v)=f\left(y_{n}+f\left(y_{n}\right)\right)-f\left(y_{n}-f\left(y_{n}\right)\right)$.

Recently Cordero et al. [2] presented a fourth-order Steffensen type method (Cordero Method):

$$
\begin{aligned}
y_{n} & =x_{n}-\frac{2 f\left(x_{n}\right)^{2}}{f\left(x_{n}+f\left(x_{n}\right)\right)-f\left(x_{n}-f\left(x_{n}\right)\right)}, \\
x_{n+1} & =x_{n}-\frac{2 f\left(x_{n}\right)^{2}}{f\left(x_{n}+f\left(x_{n}\right)\right)-f\left(x_{n}-f\left(x_{n}\right)\right)} \cdot \frac{f\left(y_{n}\right)-f\left(x_{n}\right)}{2 f\left(y_{n}\right)-f\left(x_{n}\right)} .
\end{aligned}
$$

Other Steffensen type methods and their applications are discussed in [[3], [4], [5], [6]].

The purpose of this paper is to develop a new third-order derivative-free method and give the convergence analysis. This paper is organized as follows. In Section 2, we present a new two-step third-order iterative method for solving nonlinear equations. In this method we approximate the derivative of the function by central difference quotient. The new method is free from derivative. We prove that the order of convergence of the new method is three. Numerical examples show better performance of our method in section 4 . Section 5 is a short conclusion.

\section{Development of the method and analysis of convergence}

Let us consider the third-order Newton-Steffensen method [10]:

$$
\begin{aligned}
y_{n} & =x_{n}-\frac{f\left(x_{n}\right)}{f^{\prime}\left(x_{n}\right)}, \\
x_{n+1} & =x_{n}-\frac{f\left(x_{n}\right)^{2}}{f^{\prime}\left(x_{n}\right)\left[f\left(x_{n}\right)-f\left(y_{n}\right)\right]} .
\end{aligned}
$$

Approximating the derivative $f^{\prime}\left(x_{n}\right)$ in $(2.1)$ by the central-difference

$$
f^{\prime}\left(x_{n}\right) \approx \frac{f\left(x_{n}+f\left(x_{n}\right)\right)-f\left(x_{n}-f\left(x_{n}\right)\right)}{2 f\left(x_{n}\right)},
$$

we obtain a new method free from derivatives, that we call the modified Newton-Steffensen method free from derivative (MNSDF):

$$
\begin{aligned}
y_{n} & =x_{n}-\frac{2 f\left(x_{n}\right)^{2}}{f\left(x_{n}+f\left(x_{n}\right)\right)-f\left(x_{n}-f\left(x_{n}\right)\right)}, \\
x_{n+1} & =x_{n}-\frac{2 f\left(x_{n}\right)^{3}}{\left\{f\left(x_{n}+f\left(x_{n}\right)\right)-f\left(x_{n}-f\left(x_{n}\right)\right)\right\}\left\{f\left(x_{n}\right)-f\left(y_{n}\right)\right\}},
\end{aligned}
$$

Now we are going to prove the method MNSDF has order of convergence three. 
Theorem 2.1 Let $x^{*} \in I$ be a simple zero of a sufficiently differentiable function $f: I \subseteq \Re \rightarrow \Re$ in an open interval I. If $x_{0}$ is sufficiently close to $x^{*}$, then the modified Newton-Steffensen method free from derivative defined by (2.2) has order of convergence three and satisfies the error equation (2.9).

By applying the Taylor series expansion theorem and taking account $f\left(x^{*}\right)=0$, we can write

$$
f\left(x_{n}\right)=c_{1} e_{n}+c_{2} e_{n}^{2}+c_{3} e_{n}^{3}+c_{4} e_{n}^{4}+c_{5} e_{n}^{5}+c_{6} e_{n}^{6}+c_{7} e_{n}^{7}+c_{8} e_{n}^{8}+O\left(e_{n}^{9}\right),
$$

where $c_{k}=\frac{f^{k}\left(x^{*}\right)}{\lfloor k}, k=1,2, \ldots$ and $e_{n}$ be the error in $x_{n}$ after $n$ iterations i.e. $e_{n}=x_{n}-x^{*}$;

$$
\begin{aligned}
f\left(x_{n}+f\left(x_{n}\right)\right)= & \left(c_{1}^{2}+c_{1}\right) e_{n}+\left(c_{2} c_{1}^{2}+3 c_{2} c_{1}+c_{2}\right) e_{n}^{2} \\
+ & \left(c_{3} c_{1}^{3}+3 c_{3} c_{1}^{2}+2 c_{1} c_{2}^{2}+4 c_{3} c_{1}+2 c_{2}^{2}+c_{3}\right) e_{n}^{3} \\
+ & \left(c 4+c_{2}\left(c_{2}^{2}+2 c_{1} c_{3}\right)+5 c_{1} c_{4}+5 c_{2} c_{3}+6 c_{1}^{2} c_{4}\right. \\
& \left.+4 c_{1}^{3} c_{4}+c_{1}^{4} c_{4}+6 c_{1} c_{2} c_{3}+3 c_{1}^{2} c_{2} c_{3}\right) e_{n}^{4} \\
+ & O\left(e_{n}^{5}\right) .
\end{aligned}
$$

and

$$
\begin{aligned}
f\left(x_{n}-f\left(x_{n}\right)\right)= & \left(-c_{1}^{2}+c_{1}\right) e_{n}+\left(c_{2} c_{1}^{2}-3 c_{2} c_{1}+c_{2}\right) e_{n}^{2} \\
+ & \left(-c_{3} c_{1}^{3}+3 c_{3} c_{1}^{2}+2 c_{1} c_{2}^{2}-4 c_{3} c_{1}-2 c_{2}^{2}+c_{3}\right) e_{n}^{3} \\
+ & \left(c 4+c_{2}\left(c_{2}^{2}+2 c_{1} c_{3}\right)-5 c_{1} c_{4}-5 c_{2} c_{3}+6 c_{1}^{2} c_{4}\right. \\
& \left.-4 c_{1}^{3} c_{4}+c_{1}^{4} c_{4}+6 c_{1} c_{2} c_{3}-3 c_{1}^{2} c_{2} c_{3}\right) e_{n}^{4} \\
+ & O\left(e_{n}^{5}\right) .
\end{aligned}
$$

Further more it can be easily find

$$
\begin{aligned}
& \frac{2 \cdot f\left(x_{n}\right)^{2}}{f\left(x_{n}+f\left(x_{n}\right)\right)-f\left(x_{n}-f\left(x_{n}\right)\right)} \\
& =e_{n}+\left(-c_{2} / c_{1}\right) e_{n}^{2}+\left(\left(2 c_{2}^{2}\right) / c_{1}^{2}-\left(2 c_{3}\right) / c_{1}-c_{1} c_{3}\right) e_{n}^{3} \\
& +\left(c_{2} c_{3}-4 c_{1} c_{4}-\left(3 c_{4}\right) / c_{1}-\left(4 c_{2}^{3}\right) / c_{1}^{3}+\left(7 c_{2} c_{3}\right) / c_{1}^{2}\right) e_{n}^{4} \\
& +O\left(e_{n}^{5}\right) .
\end{aligned}
$$

By considering this relation and expression of $y_{n}$ in the equation (2.2), we obtain

$$
\begin{aligned}
y_{n}= & x^{*}+\left(c_{2} / c_{1}\right) e_{n}^{2}-\left(\left(2 c_{2}^{2}\right) / c_{1}^{2}-\left(2 c_{3}\right) / c_{1}-c_{1} c_{3}\right) e_{n}^{3} \\
& -\left(c_{2} c_{3}-4 c_{1} c_{4}-\left(3 c_{4}\right) / c_{1}-\left(4 c_{2}^{3}\right) / c_{1}^{3}+\left(7 c_{2} c_{3}\right) / c_{1}^{2}\right) e_{n}^{4} \\
& +O\left(e_{n}^{5}\right) .
\end{aligned}
$$

At this time, we should expand $f\left(y_{n}\right)$ around the root by taking into consideration (2.7). Accordingly, we have

$$
\begin{aligned}
f\left(y_{n}\right)= & c_{2} e_{n}^{2}+c_{1}\left(c_{1} c_{3}+\left(2 c_{3}\right) / c_{1}-\left(2 c_{2}^{2}\right) / c_{1}^{2}\right) e_{n}^{3} \\
& +\left(c_{1}\left(4 c_{1} c_{4}-c_{2} c_{3}+\left(3 c_{4}\right) / c_{1}+\left(4 c_{2}^{3}\right) / c_{1}^{3}-\left(7 c_{2} c_{3}\right) / c_{1}^{2}\right)+c_{2}^{3} / c_{1}^{2}\right) e_{n}^{4} \\
& +O\left(e_{n}^{5}\right) .
\end{aligned}
$$

By using (2.3), (2.8), (2.4) and (2.5) in the last expression of (2.2), we obtain

$$
e_{n+1}=\left(c_{2}^{2} / c_{1}^{2}\right) e_{n}^{3}+O\left(e_{n}^{4}\right)
$$




\section{$3 \quad$ Numerical Tests}

In this section, in order to compare the our new method with Steffensen method, Jain method, Dehghan method I, Dehghan method II, Dehghan method III and Cordero method, we give some numerical examples. For this consider the following functions:

Table 1. Test functions and their roots.

\begin{tabular}{ll}
\hline Non-linear functions & Roots \\
\hline$f_{1}(x)=\sin ^{2}(x)-x^{2}+1$ & 1.404492 \\
$f_{2}(x)=x^{2}-e^{x}-3 x+2$ & 0.257530 \\
$f_{3}(x)=\cos (x)-x$ & 0.739085 \\
$f_{4}(x)=\cos (x)-x e^{x}+x^{2}$ & 0.639154 \\
$f_{5}(x)=e^{x}-1.5-\arctan (x)$ & 0.767653 \\
\hline
\end{tabular}

Table 2-6 shows the comparison of these methods for these functions. All the numerical computations have been carried out using MATHEMATICA 8. The numerical results show that the our proposed method is efficient.

Table 2. Errors Occurring in the estimates of the root of function $f_{1}(x)=\sin ^{2}(x)-x^{2}+1$ after third iteration by the method described with initial guess $x_{0}=1$.

\begin{tabular}{ll}
\hline Methods & $\left|f_{1}\left(x_{3}\right)\right|$ \\
\hline Steffensen Method & $0.27307 \mathrm{e}-3$ \\
Jain Method & $0.15974 \mathrm{e}-11$ \\
Dehghan I Method & $0.12208 \mathrm{e}-3$ \\
Dehghan II Method & $0.27058 \mathrm{e}-7$ \\
Dehghan III Method & $0.23473 \mathrm{e}-9$ \\
Cordero Method & $0.16292 \mathrm{e}-9$ \\
MNSDF & $0.22293 \mathrm{e}-12$ \\
\hline
\end{tabular}

Table 3. Errors Occurring in the estimates of the root of function $f_{2}(x)=x^{2}-e^{x}-3 x+2$ after third iteration by the method described with initial guess $x_{0}=0.7$.

\begin{tabular}{ll}
\hline Methods & $\left|f_{2}\left(x_{3}\right)\right|$ \\
\hline Steffensen Method & $0.79151 \mathrm{e}-6$ \\
Jain Method & $0.99771 \mathrm{e}-31$ \\
Dehghan I Method & $0.27162 \mathrm{e}-5$ \\
Dehghan II Method & $0.20573 \mathrm{e}-22$ \\
Dehghan III Method & $0.70112 \mathrm{e}-12$ \\
Cordero & $0.89687 \mathrm{e}-6$ \\
MNSDF & $0.82122 \mathrm{e}-31$ \\
\hline
\end{tabular}


Table 4. Errors Occurring in the estimates of the root of function $f_{3}(x)=\cos (x)-x$ after third iteration by the method described with initial guess $x_{0}=1$.

\begin{tabular}{ll}
\hline Methods & $\left|f_{3}\left(x_{3}\right)\right|$ \\
\hline Steffensen Method & $0.82149 \mathrm{e}-10$ \\
Jain Method & $0.10235 \mathrm{e}-34$ \\
Dehghan I Method & $0.17099 \mathrm{e}-23$ \\
Dehghan II Method & $0.61489 \mathrm{e}-33$ \\
Dehghan III Method & $0.19366 \mathrm{e}-28$ \\
Cordero Method & $0.14803 \mathrm{e}-15$ \\
MNSDF & $0.98665 \mathrm{e}-36$ \\
\hline
\end{tabular}

Table 5. Errors Occurring in the estimates of the root of function $f_{4}(x)=\cos (x)-x e^{x}+x^{2}$ after third iteration by the method described with initial guess $x_{0}=1$.

\begin{tabular}{ll}
\hline Methods & $\left|f_{4}\left(x_{3}\right)\right|$ \\
\hline Steffensen Method & $0.46704 \mathrm{e}-2$ \\
Jain Method & $0.15915 \mathrm{e}-10$ \\
Dehghan I Method & $0.85626 \mathrm{e}-2$ \\
Dehghan II Method & $0.40435 \mathrm{e}-7$ \\
Dehghan III Method & $0.15970 \mathrm{e}-5$ \\
Cordero Method & $0.19461 \mathrm{e}-2$ \\
MNSDF & $0.53152 \mathrm{e}-12$ \\
\hline
\end{tabular}

Table 6. Errors Occurring in the estimates of the root of function $f_{5}(x)=e^{x}-1.5-\arctan (x)$ after third iteration by the method described with initial guess $x_{0}=1$.

\begin{tabular}{ll}
\hline Methods & $\left|f_{5}\left(x_{3}\right)\right|$ \\
\hline Steffensen Method & $0.78069 \mathrm{e}-3$ \\
Jain Method & $0.99920 \mathrm{e}-15$ \\
Dehghan I Method & $0.43288 \mathrm{e}+0$ \\
Dehghan II Method & $0.11102 \mathrm{e}-15$ \\
Dehghan III Method & $0.21494 \mathrm{e}-10$ \\
CorderoMethod & $0.55888 \mathrm{e}-13$ \\
MNSDF & $0.11102 \mathrm{e}-15$ \\
\hline
\end{tabular}

\section{REFERENCES}

[1] D. Kincaid and W. Cheney: Numerical Analysis, Second Edition, Brooks/Cole, Pacific Grove, CA (1996).

[2] A. Cordero, J. L. Hueso, E. Martinez and J. R. Torregrosa: Steffensen type methods for solving non-linear equations, Journal of Computational and Applied Mathematics, 236 (2012), 3058-3064.

[3] Z. Liu, Q. Zheng, and P. Zhao: A variant of Steffensens method of fourth-order convergence and its applications. Appl. Math. Comput., 214 (2010) 1978-1983.

[4] H. Ren, Q. Wu, and W. Bi: A class of two-step Steffensen type methods with fourth-order convergence. Appl. Math. Comput., 209 (2009) 206-210 .

[5] Q. Zheng, P. Zhao, and F. Huang: A family of fourth-order Steffensen-type methods with the applications on solving nonlinear ODEs. Appl. Math. Comput., 217 (2011) 8196-8203 .

[6] M. S. Petković, and S. Ilić, and J. Džunić: Derivative free two-point methods with and without memory for solving nonlinear equations. Appl. Math. Comput., 217 (2010) 1887-1895 .

[7] P. Jain: Steffensen type methods for solving nonlinear equations, Applied Mathematics and Computation, 194 (2007) 527-533.

[8] M. Dehghan and M. Hajarian: Some derivative free quadratic and cubic convergence iterative formulas for solving nonlinear equations, Computational and Applied Mathematics, 29 (2010) 19-30.

[9] M. Dehghan and M. Hajarian: On derivative free cubic convergence iterative methods for solving nonlinear equations, Computational Mathematics and Mathematical Physics, 51 (2011) 513-519.

[10] J. R. Sharma, A composite third order Newton-Steffensen method for solving nonlinear equations, Appl. Math. Comput. 169 (2005) 242-246. 